\title{
A Double-Blind, Placebo-Controlled, Phase II Study to Determine the Efficacy, Safety, Tolerability and Pharmacokinetics of a Controlled Release (CR) Formulation of Mazindol in Adults with DSM-5 Attention-Deficit/Hyperactivity Disorder (ADHD)
}

\author{
Tim L. Wigal ${ }^{1} \cdot$ Jeffrey H. Newcorn $^{2}$ (D) Nelson Handal $^{3} \cdot$ Sharon B. Wigal $^{1}$ • \\ Ioulietta Mulligan $^{4} \cdot$ Virginia Schmith $^{5}$ (D) Eric Konofal $^{6}$ (D)
}

Published online: 19 March 2018

(C) The Author(s) 2018

\begin{abstract}
Background Mazindol is under investigation for the treatment of attention-deficit/hyperactivity disorder (ADHD) because of its alertness-enhancing properties. A novel controlled-release (CR) formulation of mazindol was developed to allow once-daily dosing.

Objective The aim of this study was to evaluate the efficacy of mazindol CR in adults with ADHD.

Design We conducted a randomized, double-blind, placebo-controlled 6-week trial.

Methods Subjects diagnosed with ADHD using the MiniInternational Neuropsychiatric Structured Interview (MINI) and with an ADHD Rating Scale, Diagnostic and Statistical Manual of Mental Disorders 5th Edition (ADHD-RS-DSM5) score $\geq 28$ were randomized to receive placebo or 1-3 mg/day of mazindol for 6 weeks. The primary endpoint was the reduction from baseline in the ADHD-RS-DSM5 score on Day 42. Secondary
\end{abstract}

Tim L. Wigal

drtim@avidainc.com

1 AVIDA Inc., 1600 Dove Street, Suite 305, Newport Beach, CA 92660, USA

2 Icahn School of Medicine at Mount Sinai, 1 Gustave L. Levy Place, New York, NY 10029-5674, USA

3 Dothan Behavioral Medicine Clinic, Harmonex Neuroscience Research, 408 Healthwest Drive, Dothan, AL 36303, USA

4 Worldwide Clinical Trials, Waterfront House, Beeston Business Park, Beeston, Nottingham NG9 1LA, UK

5 Nuventra Pharma Sciences, 2525 Meridian Parkway, Suite 280, Durham, NC 27713, USA

6 Pediatric Sleep Disorders Center, Hôpital Robert Debré, Assistance Publique-Hôpitaux de Paris (APHP), 48 Boulevard Serurier, Paris, France endpoints were response rates defined by change in ADHD-RS-DSM5 $\quad(\geq 30$ or $\geq 50 \%$ reduction $)$ and dichotomized Clinical Global Impression-Improvement (CGI-I) score (1 or 2). An exploratory endpoint of functional impairment, as measured by the Target Impairment Scale, examined individualized deficits in specific settings. Safety, tolerability, and pharmacokinetics were assessed. Results Eighty-five participants were randomized ( $n=43$ active, 42 placebo); 75 completed. Weekly ADHD-RSDSM5 measurements after mazindol differed from placebo beginning at Day 7 , with a least squares mean difference (active-placebo) of - 13.2 at Day 42 and an effect size of 1.09. For the $30 \%$ or more reduction in ADHD-RS-DSM5 (minimal response), a significant difference (active-placebo) was seen starting at Day 7 and continuing to Day 42 . For the CGI-I ( 1 or 2$)$ and for the $50 \%$ or more reduction in ADHD-RS-DSM5 (measures of excellent response), the differences began at Day 14 and continued to Day 42 . Functional impairment was significantly different in the proportion achieving at least a 50\% reduction in target impairment score (42.9\% mazindol vs $11.9 \%$ placebo) by Day 42. Dry mouth, nausea, fatigue, heart rate (HR) increased, decreased appetite, and constipation were more prevalent for mazindol versus placebo. Overall, mazindol CR had minimal effects on blood pressure and small effects on HR.

Conclusion Mazindol CR was efficacious in the treatment of adults with ADHD, with a large effect size, and was well tolerated, supporting the progression to phase III. (Clinicaltrials.gov Registration No. NCT02808104) 


\section{Key Points}

Mazindol CR is a novel, proprietary, controlledrelease formulation of a medication that was initially developed for the short-term treatment of obesity in 1973, and withdrawn from United States (US)/ European markets by 2002 due to commercial reasons (not due to safety or efficacy). When marketed, mazindol immediate release (IR) was a Schedule IV controlled substance (C4, per the US Drug Enforcement Agency [DEA]).

Mazindol CR was highly efficacious in the treatment of attention-deficit/hyperactivity disorder (ADHD) in a placebo-controlled, flexible-dose study in adults with ADHD, with a placebo-adjusted effect size of 1.09 , which is similar to efficacy with $\mathrm{C} 2$ stimulants in other studies.

Mazindol CR was well tolerated, with mild to moderate treatment-emergent adverse events (TEAEs) reported, including dry mouth, headache, nausea, fatigue, increased heart rate (HR), decreased appetite, somnolence, middle insomnia, and constipation. Overall, there were no significant changes in QTcF, minimal effects on blood pressure, a small effect on HR, and a small decrease in body weight, all similar to what has been observed with medications for ADHD in other studies.

\section{Introduction}

Attention-deficit/hyperactivity disorder (ADHD) is one of the most prevalent psychiatric disorders in children and adults worldwide. First-line pharmacological management is with psychostimulants, such as methylphenidate and amphetamine, which are Schedule II controlled substances (C2, per the US Drug Enforcement Agency [DEA]). While $\mathrm{C} 2$ stimulants are highly effective for ADHD, stimulants are misused recreationally with both diversion and abuse being common problems [1]. Furthermore, not all individuals respond optimally to or tolerate $\mathrm{C} 2$ stimulants because of adverse events [2]. Non-stimulants (e.g., atomoxetine and $\alpha-2$ agonists such as long-acting clonidine and guanfacine) are Food and Drug Administration (FDA)approved for ADHD, but efficacy, overall, is not as robust as with $\mathrm{C} 2$ stimulants [3]. Moreover, the tolerability profile is not necessarily superior to stimulants. Thus, further treatment options are needed [4].
Mazindol (5-[p-chlorophenyl]-2,5-dihydro-3H-imidazo[2,1-a] isoindol-5-ol; brand names: Sanorex, Mazanor) is an imidazo-isoindole agent that was first approved by the FDA in 1973 and then in the European Union (EU) in the 1980s for the treatment of obesity in adults; however, it was voluntarily withdrawn from both the US and EU markets by the early 2000s because of low sales. Mazindol immediate release (IR) is still approved in Mexico/Central America, Japan, and Argentina (where there is also a sustained-release formulation) for the short-term treatment of obesity. Mazindol IR has been available in the EU for compassionate use in the treatment of narcolepsy and idiopathic hypersomnias for several decades, with a favorable benefit/risk ratio [5]. When marketed in the US, mazindol IR was classified as Schedule IV by the DEA, meaning that it was considered to have a low potential for abuse and addiction.

A recent open-label study of mazindol IR $(1 \mathrm{mg} / \mathrm{day}$ for 7 days) in 21 school-aged children with ADHD yielded a change in parent-rated ADHD-Rating Scale (ADHD-RS) mean total score of $-24.6(p<0.0001)$, with $>90 \%$ improvement from baseline; there were mild to moderate adverse events (e.g., decreased appetite, headache, abdominal pain) without significant changes in laboratory values, electrocardiogram (ECG), systolic and diastolic blood pressure (SBP, DBP), heart rate (HR), and body weight [6].

Since the completion of the open-label study, a controlled release (CR) formulation of mazindol has been developed; this formulation can be administered once daily (QD), has a time to maximum concentration $\left(T_{\max }\right)$ of $4 \mathrm{~h}$ and a half-life $\left(t_{1 / 2}\right)$ of $\sim 10 \mathrm{~h}$ [7]. Based on in vitro binding studies at $10 \mu \mathrm{M}(>600 \times$ maximum concentration $\left[C_{\max }\right]$ at $16.5 \mathrm{nM}$ after mazindol $3 \mathrm{mg}$ ), mazindol is a serotonin-, noradrenaline-, and dopamine-reuptake inhibitor (SNDRI), with $>99 \%$ binding at each of the three transporters, and an agonist with $>50 \%$ binding at the serotonin 5-HT1A and 5-HT7 receptors, muscarinic receptors, the histamine $\mathrm{H} 1$ receptor, and the $\mu$-opioid receptor. Notably, mazindol also has $39 \%$ binding at orexin-2 receptors (i.e., partial agonist). The potency of the hydrolysis metabolite (2-[2-Aminoethyl]-3-[ $p$-chlorophenyl]-3-hydroxyphthalimidine) is similar to the parent compound (data on file).

Although the exact mechanism of action is uncertain, the pharmacologic profile of mazindol suggests that it might be useful for treating ADHD. Mazindol CR is unique from other available medications for ADHD because none of the currently approved pharmacological treatments are considered SNDRIs, nor do they promote a regulatory effect on 5-HT1A, 5-HT7, or the hypothalamic orexin system. Orexin fibers are dense in brain regions crucial for wakefulness and arousal, particularly the locus coeruleus 
that contains adrenergic, noradrenergic, histaminergic, and serotonergic neurons. Orexin neuropeptides are known to play important modulatory roles in sleep/wake regulation, motivation, reward, as well as emotional and attentional regulation [8].

A well controlled phase II study of mazindol CR in adults with ADHD was designed based on what is known about the mechanism of action and dosing requirements for mazindol IR, previous compassionate use in the treatment of narcolepsy in the EU [5, 9, 10], the large safety database from previous and present worldwide use, and positive preliminary data for pediatric ADHD_all with the IR formulation. The goal of this 6-week study was to evaluate the efficacy, safety, tolerability, and pharmacokinetics of mazindol CR in adults with ADHD. The primary hypothesis was that adults with ADHD receiving mazindol CR dosed flexibly from 1 to $3 \mathrm{mg}$ QD compared with placebo would show greater improvement in ADHD symptoms as measured by the DSM5 ADHD-RS mean total score.

\section{Methods}

This was an outpatient, randomized, double-blind, placebocontrolled study in which subjects were randomized 1:1 to receive oral mazindol $\mathrm{CR}$ or placebo QD. Eighty-four subjects were planned to be randomized (42 to each of two treatment arms) at seven clinical sites in the US. The study was approved by Schulman Institutional Review Board and was performed in accordance with International Conference on Harmonization-Good Clinical Practice (ICH-GCP) guidelines (ClinicalTrials.gov Registration No. NCT02808104).

\subsection{Inclusion/Exclusion Criteria}

Subjects were 18-65 years of age, with a primary diagnosis of ADHD based upon the Mini International Neuropsychiatric Interview 7.0 (MINI) with the ADHD module [11]. This interview, updated for the Diagnostic and Statistical Manual of Mental Disorders, Fifth Edition (DSM5) criteria [12], was performed by licensed clinicians trained in its administration. In addition, clinicians were trained to administer the ADHD-RS for DSM5 (ADHD-RS-DSM5), the Clinical Global Impressions-Severity Scale (CGI-S), the Clinical Global Improvement Scale (CGI-I), and the Target Impairment Scale. Adults had a minimum score of 28 on the ADHD-RS-DSM5 and a minimum score of 4 (moderate) on the CGI-S when not taking any ADHD medications for at least 14 days. They were in good general physical health; tested negative for pregnancy (urine; females only); used acceptable methods of contraception (females of child-bearing potential only); were fluent in spoken and written English; were able to follow protocol requirements; and provided informed consent.

The MINI 7.0 was also used to help make a diagnosis of other psychiatric conditions. Subjects were excluded if they had any current DSM5 disorder other than ADHD which required treatment, or a lifetime history of bipolar disorder or other psychotic disorder; were taking any prohibited concomitant medication (e.g., antidepressants, antipsychotics, mood stabilizers, anti-epileptics, cardiovascular agents, sedating antihistamines or decongestants, sensitive CYP3A4 or CYP2D6 substrates with narrow therapeutic indices, strong CYP3A4 inducers or inhibitors, and concomitant gastric $\mathrm{pH}$ modulators) including other ADHD medications (if not discontinued for at least 14 days); or had any concurrent condition that would interfere with study procedures; clinically significant ECG abnormality or a QTc (Bazett correction) interval $>450 \mathrm{~ms}$; resting sitting $\mathrm{SBP}>150 \mathrm{mmHg}$ or $\mathrm{DBP}>90 \mathrm{mmHg}$; body mass index $<18$ or $>40 \mathrm{~kg} / \mathrm{m}^{2}$; positive urine drug screen (UDS); pregnant or lactating; active suicidal ideation within 3 months of screening or suicidal behavior within a year of screening (i.e., score $\geq 3$ on the ideation subscale of the Columbia-Suicide Severity Rating Scale [C-SSRS]); clinically significant out-of-range laboratory value, medical history, or physical examination finding that contraindicated enrollment; significant drug allergy or systemic allergic disease; or any known/suspected hypersensitivity to any form of mazindol.

\subsection{Study Design}

A screening visit occurred within 4-21 days prior to randomization. All subjects were treated for a total of 6 weeks and had visits on Days 0, 7, 14, 21, 28, 35, and 42 to undergo assessments for efficacy and safety. Each visit (except Day 0) occurred within \pm 3 days of the scheduled weekly visit. A follow-up phone call occurred 7-10 days after the last dose of study treatment.

Mazindol CR was dosed flexibly. On Day 0, subjects began taking mazindol CR $1 \mathrm{mg}$ or placebo QD for the first week. Depending upon clinical response and tolerability, investigators could increase the dose of mazindol CR (or corresponding blinded placebo) to $2 \mathrm{mg}$ QD for the second week, and possibly again to $3 \mathrm{mg}$ QD for the third week. At each visit, the dose could be held or reduced per the investigator's clinical judgment. Dosage adjustments could not exceed increments of $>1 \mathrm{mg} /$ day/week. Participants were to remain on a fixed dose for the final 4 weeks (similar to most acute ADHD trials of stimulants), with dose reductions allowed due to lack of tolerability (which occurred in four subjects).

Mazindol CR was administered as $1 \mathrm{mg}, 2 \mathrm{mg}$, or $3 \mathrm{mg}$ tablets, all (including placebo) manufactured to look 
identical. Medication containers were to be returned at each study visit for drug accountability. Compliance was assessed by tablet counts; noncompliance was defined as being off study medication for $>6$ consecutive days during the study.

The rationale for the dose selection for this study was based on (1) predicting a dose in adults that would have a sufficient probability of achieving an area under the curve during a dosing interval $\left(\mathrm{AUC}_{0-\tau}\right)$ and maximum plasma concentrations $\left(C_{\max }\right)$ that were similar to those achieved in pediatric subjects receiving mazindol IR $1 \mathrm{mg}$ QD, where efficacy had been demonstrated in an open-label trial [6]; (2) predicting a dose of mazindol $\mathrm{CR}$ that would result in exposures $\left(\mathrm{AUC}_{0-\tau}\right)$ and $C_{\max }$ that did not exceed $1 / 5$ th the no-observed-adverse-effect level (NOAEL) for dogs in at least $97.5 \%$ of subjects; and (3) the extensive safety data outlined in the summary basis of approval for Mazanor and Sanorex for doses up to $3 \mathrm{mg}$ daily (administered as divided doses). The upward sequential dose titration was chosen to mimic standard clinical practice.

\subsection{Assessments and Endpoints}

Efficacy was assessed weekly using the ADHD-RS-DSM5, the CGI-I scale, and the Target Impairment Scale (see Table 1). The Target Impairment Scale collected clinically meaningful information from each participant, in a standardized manner, on three functional deficits deemed to be meaningful for that individual [19]. The Target Impairment Scale was used to establish a common understanding with each subject concerning treatment goals related to ADHD symptomology, and to provide an individualized measure of functional outcome. The ADHD Target Impairment Scale provided both a contextual and functional anchor for the subsequent clinician administration of both the ADHDRS-DSM5 and the CGI-I at each weekly visit, and provided an additional method to assess response to treatment. The degree of correspondence (Pearson correlation) between the Target Impairment Scale and both the CGI-I $(r=0.818)$ and the ADHD-RS-DSM5 $(r=0.824)$ was strong and suggestive of good concurrent validity.

The primary endpoint was the change from baseline (CFB) of mazindol CR versus placebo in the ADHD-RSDSM5 score at Day 42. Secondary efficacy endpoints included responder status as measured by the ADHD-RSDSM5 ( $\geq 30 \%$ [minimal response threshold] or $\geq 50 \%$ [excellent response threshold] CFB), and responder status as measured by dichotomized CGI-I (score of 1 or 2) for mazindol CR versus placebo, as well as the time course of change in ADHD-RS-DSM5 scores and responder status for mazindol $\mathrm{CR}$ versus placebo. The proportion of responders with $\mathrm{a} \geq 50 \% \mathrm{CFB}$ in ADHD Target
Impairment scores for mazindol CR versus placebo was an exploratory endpoint.

Safety assessments included spontaneously reported adverse events (AEs); vital signs, body weight, and the $\mathrm{C}-$ SRSS at all visits; 12-lead ECG (most visits); and physical examination and clinical laboratory evaluations (at screening and Day 42).

Resting vital signs (HR, SBP, and DBP) were collected at predose and $2 \mathrm{~h}$ postdose on Days 1 and 42 and at nonspecified times at each visit, with each recording made after the subject had been sitting for at least $5 \mathrm{~min}$.

Pharmacokinetic assessments were obtained at predose, 1 and $2 \mathrm{~h}$ postdose on Day 1 and Day 42, and at a single time point on Days 7, 14, and 21. An optional pharmacokinetics subgroup had additional samples collected on Day 42 (only) at 3, 4 (optional), and 5 (optional) hours after the last dose.

\subsection{Statistical Methods}

The primary efficacy assessment, CFB in the ADHD-RSDSM5 score at Day 42, was evaluated using a mixed-effect model repeated measures analysis, which included fixed effects of treatment, theoretically important and typically applied covariates (e.g., sex, baseline ADHD-RS-DSM5 score), and a treatment-by-visit interaction as well as a random effect of variability by subject on the intent-to-treat population (ITT; all randomized subjects who had been administered study treatment, and had at least one postbaseline assessment). The statistical analysis plan stated that model assumptions were to be examined and alternative analyses (e.g., analysis after data transformation or non-parametric analysis) could be performed as appropriate. In actuality, no alternative analyses were performed, as model assumptions were tested and were found to be appropriate to the chosen analysis. Least squares (LS) means, 95\% confidence intervals (CIs), $p$ values of the treatment comparisons (across and within visits), and basic arithmetic summary statistics were provided. The analysis was repeated for the per protocol (PP) population (those in the ITT population with no major protocol deviations affecting the primary efficacy variable, defined prior to unblinding) who completed the protocol.

For sensitivity analyses only, the primary efficacy endpoint using observed data and the last observation carried forward (LOCF) was assessed using an analysis of covariance (ANCOVA) with factors for treatment, sex, and baseline ADHD-RS-DSM5 score. In addition, analyses of the primary efficacy endpoint were examined in relation to sex, age, baseline CGI-S score, and ADHD clinical presentation.

The placebo-adjusted effect size was calculated using the mean difference in ADHD-RS-DSM5 scores between 
Table 1 ADHD Target Impairment Scale

\begin{tabular}{|l|l|l|l|}
\hline Date: & Visit\#: & Rater Initials: & Client ID: \\
\hline $\begin{array}{l}\text { Client's overall rating for } \\
\text { “week": } \\
\text { (1-10 with } 10 \text { best) }\end{array}$ & Days since last visit: & \\
& & & \\
\hline
\end{tabular}

\begin{tabular}{|l|l|l|l|l|}
\hline $\begin{array}{l}\text { SETTINGS OF } \\
\text { IMPAIRMENT: } \\
\text { Home, Social, } \\
\text { Work, School (or } \\
\text { personal) }\end{array}$ & $\begin{array}{l}\text { TARGETS } \\
\text { client-generated } \\
\text { descriptions }\end{array}$ & $\begin{array}{l}\text { ADHD-related DSM5 } \\
\text { @ Symptom }\end{array}$ & $\begin{array}{l}\text { FREQUENCY: } \\
\text { jumber of } \\
\text { occurrences/ } \\
\text { judged by clinician } \\
\text { (either per day or } \\
\text { week }\end{array}$ & $\begin{array}{l}\text { CURRENT } \\
\text { SEVERITY } \\
\text { 0-none } \\
\text { 1-mild } \\
\text { 2 -mod } \\
\text { 3- severe }\end{array}$ \\
\hline 1. & & & & \\
\hline 2. & & & & \\
\hline 3. & & & & \\
\hline 4. (If Needed) & & & & \\
\hline
\end{tabular}

Abbreviations: ADHD = Attention-Deficit/Hyperactivity Disorder; DSM5 = Diagnostic and Statistical Manual of Mental Disorders, Fifth Edition

NOTE: Severity rating combines frequency and level of impairment

Three questions to help client generate targets at baseline:

If this treatment works, what things do you hope will be better in your daily life?

What's not going the way you would like it to go on a daily basis?

What tasks/activities take more effort than you feel they should?

Reminder: Targets (and related symptoms) remain the same after baseline visit

arms from baseline to Day 42 and dividing this by the pooled standard deviation on Day 42. In terms of total ADHD-RS-DSM5 score, for a two-sample pooled $t$ test of a normal mean difference with a two-sided significance level of 0.05 , assuming a common standard deviation of 14 , a sample size of 42 per group has a power of 0.804 to detect a mean difference of 8.7. This power calculation is based on previous data where the mean change from baseline in the ADHD-RS-IV for an approved ADHD agent is -19.7 , while the mean change from baseline for placebo is -11 [14].

For responder analyses, repeated measures over time were fit using generalized estimating equations and the procedure for generalized linear models in SAS. Factors included in the model were treatment, sex, visit, treatmentby-visit interaction, and baseline ADHD-RS-DSM5 score. As sensitivity analyses, logistic regression models were fit on all four responder endpoints on Day 42. In the sensitivity analysis, subjects who did not complete the doubleblind period were considered non-responders.

Subjects were to be randomized 1:1 to mazindol CR or placebo, stratified by sex, with the constraint that no more than $75 \%$ of the total randomized subjects were male and that no more than $45 \%$ were female. Interactive Response Technology (IRT) was utilized as the central screening and randomization methodology to maintain the balanced 
Table 2 Demographics-safety population

\begin{tabular}{lll}
\hline Parameter & $\begin{array}{l}\text { Mazindol CR 1-3 mg } \\
N=43\end{array}$ & $\begin{array}{l}\text { Placebo } \\
N=42\end{array}$ \\
\hline Sex (\% male/ \% female) & $41.9 / 58.1$ & $42.9 / 57.1$ \\
Race (\% White/ \% Black or African American/ \% Asian/ \% Other) & $81.4 / 14 / 2.4 / 0$ & $81 / 11.9 / 2.4 / 2.4$ \\
Age in years [mean \pm SD (min, max)] & $32.6 \pm 8.62(18,52)$ & $34.7 \pm 11.87(18,63)$ \\
ADHD subtype (\% combined/ \% inattention) & $79.1 / 20.9$ & $88.1 / 11.9$ \\
ADHD-RS-DSM5 at baseline [mean \pm SD (min, max)] & $38.2 \pm 5.96(28,52)$ & $40.2 \pm 4.69(32,49)$ \\
\hline
\end{tabular}

$A D H D$ attention-deficit/hyperactivity disorder, $A D H D-R S$-DSM5 Attention-Deficit/Hyperactivity Disorder Rating Scale for DSM-5, $C R$ controlled release, $S D$ standard deviation

allocation of treatment across sex stratification by sex, and preserve the blind to avoid bias. A technical programming error in the IRT system development resulted in the enrollment of more females than planned (49 females; 36 males), and a human error during subject registration in the IRT system ultimately resulted in the enrollment of 85 rather than 84 subjects. Analysis of unblinded data by sex showed an evenly balanced treatment allocation of subjects across sexes (Table 2). A Monte Carlo simulation bootstrapping approach using simulated baseline/Day 42 data showed no statistical differences between the findings based on observed data and data simulated by protocolspecified sex allocation.

Safety and tolerability were summarized by treatment, visit, and time since last dose, when appropriate. The incidence and severity of treatment-emergent adverse events (TEAEs) were summarized by treatment group for the safety population. Vital signs, weight, ECG data, clinical laboratory values, and C-SSRS data were summarized using the observed and CFB values with descriptive statistics, by treatment group and visit/time.

The concentrations of mazindol and the hydrolysis metabolite were summarized using descriptive statistics and were compared with concentration-time profiles predicted from healthy volunteers receiving mazindol CR [7].

\section{Results}

Figure 1 summarizes the disposition of study subjects. One subject withdrew consent before the first assessment point, and contributed no post-baseline efficacy data. Therefore, the ITT population included 84 subjects and the safety population included 85 subjects. The PP population consisted of 79 subjects. Those excluded from the PP population included one mazindol CR-treated subject who withdrew 4 days into the study, three subjects who were not compliant with study treatment $(n=2$ on mazindol CR and $n=1$ on placebo), one placebo-treated subject who used prohibited medications and withdrew early due to a positive drug screen, and one placebo-treated subject who took concomitant medications that could increase attention or cause drowsiness at baseline or on Day 42 .

By end of treatment, all subjects on mazindol CR were titrated to either $2 \mathrm{mg}$ QD $(n=10)$ or $3 \mathrm{mg}$ QD $(n=31)$ as their top dose (see Fig. 1). Of subjects receiving mazindol CR, 28\% were ADHD-medication naïve, $60.5 \%$ had previously received stimulants, and $11.5 \%$ had previously received non-stimulants according to information provided by subjects (generally via phone screens).

\subsection{Baseline Characteristics}

The demographics are summarized in Table 2. The mean score on the ADHD-RS-DSM5 at baseline was 39.3 (range $28-52$ ), with $42.4 \%$ of subjects rated as moderately ill, $50.6 \%$ markedly ill, and $7 \%$ severely ill on the CGI-S scale. There were no significant differences in baseline ADHD-RS-DSM5 score or sex between treatments.

\subsection{Efficacy}

The mean CFB in the ADHD-RS-DSM5 score at Day 42 was statistically significant for mazindol CR versus placebo $(p<0.001)$. The LS mean improvements in subjects' scores were -18.9 (mazindol CR) and -5.7 (placebo) with a higher LS mean improvement (mazindol CR-placebo) score of -13.2 (95\% CI -18.7 to -7.6$)$ and an overall placebo-corrected effect size of 1.09 (ITT population). Analysis of data from the PP population were nearly identical to the results from the ITT population, with a LS mean improvement (mazindol CR-placebo) score of 13.7 (95\% CI -19.4 to -8.0$)(p<0.001)$.

Mazindol CR showed a significant difference versus placebo as early as Day 7 (Table 3, Fig. 2). There was a significant treatment-by-visit interaction, with treatment differences at each visit becoming increasingly larger in favor of mazindol CR. 


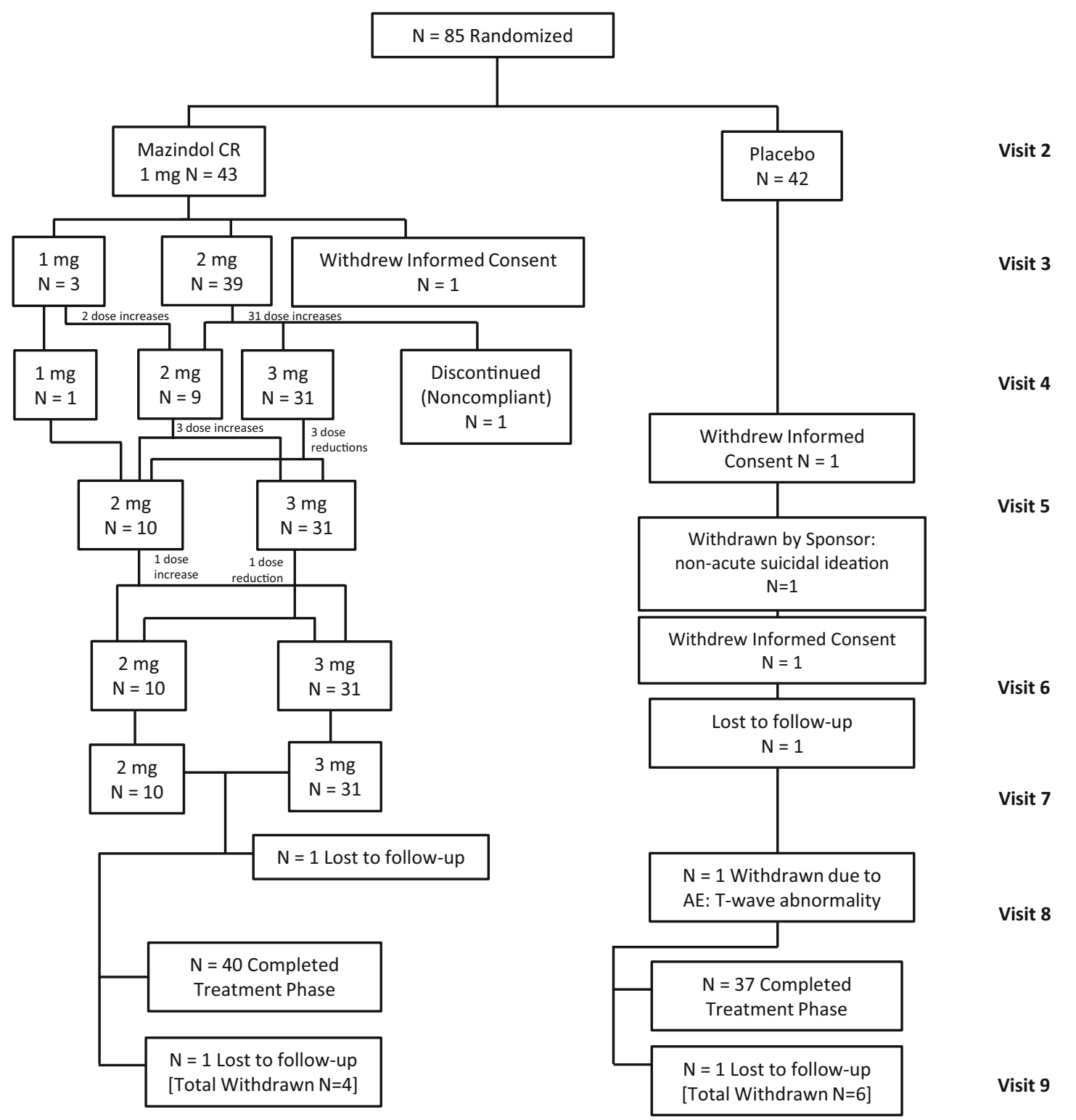

Fig. 1 Disposition of participants. $A E$ adverse event, $C R$ controlled release

Sensitivity analyses confirmed a similar improvement following mazindol CR versus placebo. Analysis by subgroup showed that sex, age, and ADHD clinical presentation were not significant covariates and thus were not significant moderators of response. Treatment and visit were both highly significant, and a treatment-by-visit interaction $(p=0.028)$ was present indicating improvement over time in the mazindol CR group but not in the placebo group.

There was a significant $(p<0.001)$ improvement in ADHD-RS-DSM5 scores by Day 42 for mazindol CR compared with placebo. Significantly more minimal responders (defined as a $\geq 30 \%$ reduction from baseline in ADHD-RS-DSM5 scores) were present in those receiving mazindol CR compared with placebo at the first assessment point (Day 7) and at each subsequent assessment, and significantly more excellent responders (defined as a $\geq 50 \%$ reduction from baseline in ADHD-RS-DSM5 score) compared with placebo were present by Day 14 and at each subsequent assessment point (Table 4). The excellent response by Day 14 was also evident in the CGI-I analysis, which indicated significantly more CGI-I responders (CGI-I score of 1 or 2) on mazindol CR compared with placebo on Day 14 and at each subsequent visit $(p \leq 0.003)$. Sensitivity analyses, assuming all subjects who did not complete the study were non-responders, resulted in a similar magnitude of difference between mazindol CR and placebo for all responder definitions.

Every subject had an ADHD Target Impairment score of 2 (moderate) or 3 (severe) at baseline. The majority of 
Table 3 Primary endpoint-repeated measures mixed-effects model on the change from baseline in the ADHD-RS-DSM5 total score (intent-totreat population)

\begin{tabular}{|c|c|c|c|c|c|}
\hline \multirow[t]{2}{*}{ Visit } & \multirow[t]{2}{*}{ LS mean mazindol CR (1-3 mg) } & \multirow[t]{2}{*}{ LS mean placebo } & \multicolumn{3}{|c|}{$\begin{array}{l}\text { Difference between LS means (mazindol CR [1-3 mg] } \\
\text { placebo) }\end{array}$} \\
\hline & & & Mean & $95 \% \mathrm{CI}$ & $p$ value \\
\hline Visit 3 (Day 7) & -8.7 & -3.6 & -5.1 & -8.7 to -1.6 & 0.005 \\
\hline Visit 4 (Day 14) & -13.5 & -5.7 & -7.8 & -12.0 to -3.6 & $<0.001$ \\
\hline Visit 5 (Day 21) & -16.8 & -6.6 & -10.1 & -15.3 to -5.0 & $<0.001$ \\
\hline Visit 6 (Day 28) & -18.5 & -6.4 & -12.2 & -17.0 to -7.3 & $<0.001$ \\
\hline Visit 7 (Day 35) & -18.9 & -6.3 & -12.7 & -17.8 to -7.5 & $<0.001$ \\
\hline \multicolumn{6}{|c|}{ Primary comparison } \\
\hline Visit 8 (Day 42) & -18.9 & -5.7 & -13.2 & -18.7 to -7.6 & $<0.001$ \\
\hline
\end{tabular}

Total scores range from 0 to 54 , a lower score is favorable

ADHD-RS-DSM5 Attention-Deficit/Hyperactivity Disorder Rating Scale, Diagnostic and Statistical Manual of Mental Disorders, 5th Edition, $C I$ confidence interval, $C R$ controlled release, $L S$ least squares

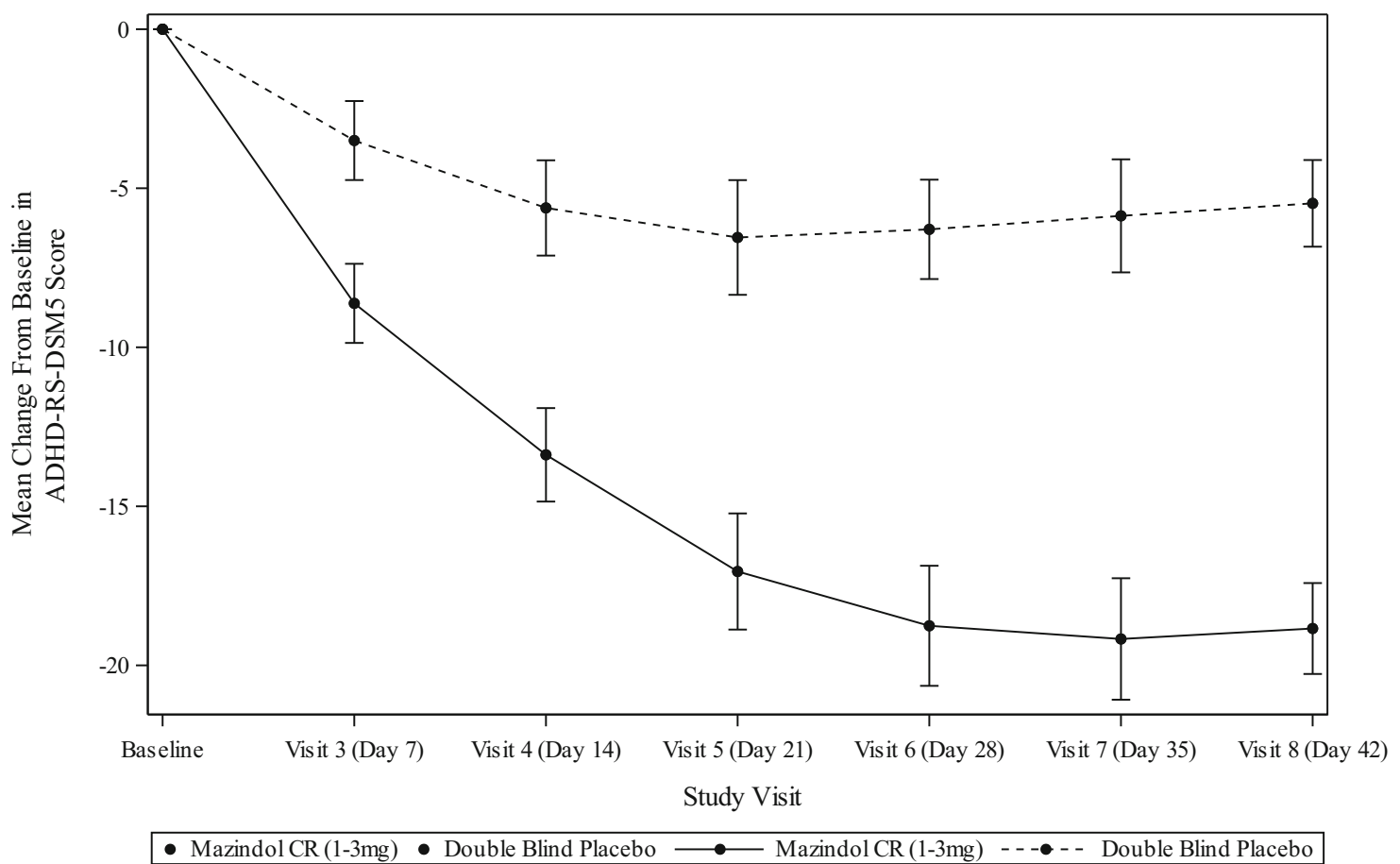

Fig. 2 Mean profiles for ADHD-RS-DSM5 score by treatment: intent-to-treat population. Bars represent standard error. ADHD-RS-DSM5 Attention-Deficit/Hyperactivity Disorder Rating Scale for DSM-5, $C R$ controlled release

targets (e.g., "leaving things behind when departing the house," "failing to finish expense reports at work," "always late for picking up the kids after school") were based on inattentive symptoms (83\%), and all 18 symptoms except "Can't be quiet in leisure activities" were identified as related to functional impairment by at least one adult. The proportion reporting at least a $50 \%$ reduction in the target score by Day 42 was $42.9 \%$ of subjects on mazindol CR compared with $11.9 \%$ on placebo; the difference between treatments was statistically significant $(p=0.002)$.

\subsection{Safety and Tolerability}

In general, mazindol CR was well tolerated and there were no deaths or serious TEAEs reported. Additionally, 42, 38, and $57 \%$ of subjects receiving mazindol CR $1 \mathrm{mg}, 2 \mathrm{mg}$, and $3 \mathrm{mg}$ QD, respectively, had TEAEs, while 21, 12, and $36 \%$ of patients receiving placebo during identical time 
Table 4 Proportion of responders defined as a 30\% reduction in ADHD-RS-DSM5 score, a 50\% reduction in ADHD-RS-DSM5 score, and a CGI responder (Score of 1 or 2) by week

\begin{tabular}{llll}
\hline Visit & $\begin{array}{l}\text { Reduction of } \geq 30 \% \text { in ADHD-RS-DSM5 } \\
\text { score (mazindol CR vs placebo) }(\%)\end{array}$ & $\begin{array}{l}\text { Reduction of } \geq 50 \% \text { in ADHD-RS-DSM5 } \\
\text { score (mazindol CR vs placebo) }(\%)\end{array}$ & $\begin{array}{l}\text { CGI }=1 \text { or } 2 \\
(\text { mazindol CR vs placebo) }(\%)\end{array}$ \\
\hline Day 7 & 33.3 vs $11.9^{\mathrm{a}}$ & 14.3 vs 4.8 & 21.4 vs 11.9 \\
Day 14 & 54.8 vs $11.9^{\mathrm{b}}$ & 33.3 vs $9.5^{\mathrm{c}}$ & $45.2 \mathrm{vs} 11.9^{\mathrm{e}}$ \\
Day 21 & 65.9 vs $26.2^{\mathrm{b}}$ & 53.7 vs $9.5^{\mathrm{b}}$ & $58.5 \mathrm{vs} 11.9^{\mathrm{b}}$ \\
Day 28 & 68.3 vs $26.8^{\mathrm{b}}$ & 58.5 vs $9.8^{\mathrm{b}}$ & $63.4 \mathrm{vs} 14.6^{\mathrm{b}}$ \\
Day 35 & 70.7 vs $18.4^{\mathrm{b}}$ & 53.7 vs $13.2^{\mathrm{d}}$ & $61.0 \mathrm{vs} 18.4^{\mathrm{b}}$ \\
Day 42 & 70.0 vs $21.1^{\mathrm{b}}$ & $55.0 \mathrm{vs} 15.8^{\mathrm{d}}$ & $62.5 \mathrm{vs} 21.1^{\mathrm{b}}$ \\
\hline
\end{tabular}

ADHD-RS-DSM5 Attention-Deficit/Hyperactivity Disorder Rating Scale for DSM-5, CGI Clinical Global Impressions score, CR controlled release

${ }^{\mathrm{a}} p=0.034 ;{ }^{\mathrm{b}} p<0.001 ;{ }^{\mathrm{c}} p=0.018 ;{ }^{\mathrm{d}} p=0.002 ;{ }^{\mathrm{e}} p=0.003$

periods, respectively, had TEAEs (Table 5). The following Medical Dictionary for Regulatory Activities (MedDRA,Version 20)-defined TEAEs were more prevalent ( $\geq 5 \%$ more than placebo) for mazindol CR compared with placebo: dry mouth, nausea, fatigue, HR increased, decreased appetite, and constipation, while the number reporting upper respiratory tract infections, decreased appetite, and headaches were similar across treatments.

The proportion of participants with any TEAE and with an $\mathrm{AE}$ of increased $\mathrm{HR}$ was higher in participants receiving mazindol CR $3 \mathrm{mg} /$ day than the other mazindol doses. No other TEAEs were more common with higher dose, including dry mouth (the most common TEAE, Table 5).

Relative to placebo, on Day 42, the mazindol CR group had a minimal (means of $\sim 3-6 \mathrm{mmHg}$ ) increase in DBP and SBP; a small increase in HR (means of $\sim 7.5$ to $11 \mathrm{bpm}$ ); and no significant changes in QTcF (corrected QT interval using Fridericia's formula), PR interval, and QRS complex (Table 6). There were no remarkable findings on physical examination, hematology, serum chemistry, or urinalysis values from baseline to Day 42 between mazindol CR and placebo. Subjects receiving mazindol CR showed a trend of decreasing body weight as early as Day 7 , and by Day 42 there was a mean weight loss for the mazindol CR group $(-1.73 \mathrm{~kg}$; range -9.6 to +3.7$)$ and a mean weight gain for the placebo group $(1.07 \mathrm{~kg}$; range 2.0 to +11.0$)$.

There were four instances of dose adjustments due to lack of tolerability (two with headache and one with nausea in subjects receiving mazindol CR; decreased appetite and headache in one placebo-treated subject); tolerability improved in subjects with dose reductions. There were no changes in the C-SSRS in participants receiving mazindol $\mathrm{CR}$. One subject receiving placebo had non-acute suicidal ideation reported at Day 21 and was withdrawn prior to Day 28.

\subsection{Pharmacokinetics}

Trough concentrations of the hydrolysis metabolite $(4.37 \pm 2.59 \mathrm{ng} / \mathrm{mL})$ were equal to or higher than mazindol trough concentrations $(1.47 \pm 1.50 \mathrm{ng} / \mathrm{mL})$ after steady-state dosing with mazindol CR on Day 42.

\section{Discussion}

The results of this study provide the first evidence that mazindol CR is efficacious and well tolerated in adults with ADHD. Mazindol $\mathrm{CR}$ had a robust effect on ADHD symptoms, with a large placebo-adjusted effect size of 1.09. The magnitude of this effect was comparable to what is typically seen with stimulants, such as methylphenidate CR [15-17], lisdexamfetamine [19, 18], d-amphetamine extended release (XR) [20], and mixed amphetamine salts [21], and much higher than for atomoxetine [22]. The LS mean difference between mazindol CR and placebo on Day 42 was found to be consistent across all sensitivity analyses, establishing that the large effect size was not biased by any of the statistical methods used.

In addition, onset of action was rapid; separation from placebo was seen at the first post-treatment data point, after 1 week of treatment. Further, there was a significantly higher proportion of excellent responders $(\geq 50 \%$ reduction in baseline scores) and responders on the CGI-I (much or very much improved) by Day 14; this finding stands in contradistinction to time to onset of effect for FDA-approved nonstimulant agents (e.g., atomoxetine, guanfacine, and clonidine), which can take up to 4 weeks to achieve efficacy [14, 23, 24]. Since subjects received mazindol CR $1 \mathrm{mg}$ QD for the first 7 days, these findings indicate that there was a clinical response at even the lowest dose. However, most subjects received $2 \mathrm{mg}$ QD for the next 7 days and then $3 \mathrm{mg}$ QD starting on Day 14. As shown in 
Table 5 Treatment-emergent adverse events in $\geq 5 \%$ of subjects in either treatment group by dose at onset of event (safety population)

\begin{tabular}{|c|c|c|}
\hline Primary system organ class/preferred term & $\begin{array}{l}\text { Mazindol CR } \\
n(\%)\end{array}$ & $\begin{array}{l}\text { Placebo } \\
n(\%)\end{array}$ \\
\hline Dose at onset day: $1 \mathrm{mg} / \mathrm{day}$ & $N=43$ & $N=42$ \\
\hline Subjects with any TEAEs & $18(41.9)$ & $9(21.4)$ \\
\hline Gastrointestinal disorders and administration site conditions & $5(11.6)$ & $2(4.8)$ \\
\hline Dry mouth & $4(9.3)$ & $1(2.4)$ \\
\hline Metabolism and nutrition disorders & $3(7.0)$ & $1(4.8)$ \\
\hline Decreased appetite & $3(7.0)$ & $1(2.4)$ \\
\hline General disorders and administration site conditions & $4(9.3)$ & $1(2.4)$ \\
\hline Fatigue & $4(9.3)$ & $1(2.4)$ \\
\hline Nervous system disorders & 5 (11.6) & $4(9.5)$ \\
\hline Headache & $3(7.0)$ & $3(7.1)$ \\
\hline Dose at onset day: $2 \mathrm{mg} / \mathrm{day}$ & $N=42$ & $N=42$ \\
\hline Subjects with any TEAEs & $16(38.1)$ & $5(11.9)$ \\
\hline Gastrointestinal disorders & $5(11.9)$ & $1(2.4)$ \\
\hline Dry mouth & $3(7.1)$ & 0 \\
\hline Dose at onset day: $3 \mathrm{mg} / \mathrm{day}$ & $N=35$ & $N=39$ \\
\hline Subjects with any TEAEs & $20(57.1)$ & $14(35.9)$ \\
\hline Gastrointestinal disorders & $9(25.7)$ & $4(10.3)$ \\
\hline Constipation & $2(5.7)$ & 0 \\
\hline Dry mouth & $3(8.6)$ & $1(2.6)$ \\
\hline Nausea & $3(8.6)$ & 0 \\
\hline Infections and infestations & $5(14.3)$ & $5(12.8)$ \\
\hline Upper respiratory tract infection & $2(5.7)$ & $2(5.1)$ \\
\hline Viral upper respiratory tract infection & $1(2.9)$ & $2(5.1)$ \\
\hline Investigations & $4(11.4)$ & $1(2.6)$ \\
\hline Heart rate increased & $3(8.6)$ & 0 \\
\hline Nervous system disorders & $5(14.3)$ & $4(10.3)$ \\
\hline Dizziness & $1(2.9)$ & $2(5.1)$ \\
\hline Headache & $3(8.6)$ & $2(5.1)$ \\
\hline
\end{tabular}

Percentages are based on the number of subjects receiving the respective dose in each treatment group Adverse events are coded using MedDRA Version 19.0

$C R$ controlled release, $N$ number of subjects in the population, $n$ number of subjects in the sample, TEAEs treatment-emergent adverse events
Fig. 2, the maximum benefit is likely observed within 2-3 weeks of beginning the most efficacious dose (typically 2 or $3 \mathrm{mg}$ ) based on the weekly dose titration approach used in this study.

One unique feature of this study was the use of an individualized measure to identify functionally relevant impairment (the Target Impairment Scale). It is noteworthy that mazindol CR produced improvement in this measure as well as the symptom ratings. Linking symptomatic improvement to functional outcomes has considerable importance for understanding the impact of treatment on the day-to-day lives of patients [25].

Mazindol CR was well tolerated, with no serious AEs reported, no discontinuations due to TEAEs, and no effects on QTcF. Not surprisingly, mazindol CR had a small effect on HR and a minimal effect on BP. The changes in HR and
$\mathrm{BP}$ after mazindol $\mathrm{CR}$ are in the range of those reported in several studies of $\mathrm{C} 2$ stimulants (e.g., mean changes of +5 to $15.8 \mathrm{bpm}$ with lisdexamfetamine [26] and methylphenidate [27, 28]) and atomoxetine [29].

Mazindol CR resulted in a small mean decrease in body weight $(\sim 1.7 \mathrm{~kg})$ by Day 42 . This is not surprising, since mazindol was initially approved for the short-term treatment of obesity. However, in the past, the effects of mazindol IR on weight loss were found to be short-lived [30], and it is assumed that the weight loss with mazindol CR seen in this study would similarly be short-lived. This awaits further study in longer-term trials.

The new pharmacokinetic finding in this study was that the hydrolysis metabolite had trough concentrations at steady-state that were higher than that of mazindol. Given the activity of the hydrolysis metabolite in the in vitro 
Table 6 Maximum change from baseline values on Day 42 (visit 8) for vital signs and electrocardiogram parameters

\begin{tabular}{|c|c|c|c|c|c|c|c|c|c|c|c|c|}
\hline \multirow[t]{3}{*}{ Parameter } & \multicolumn{6}{|c|}{ Mazindol CR $(1-3 \mathrm{mg})(N=43)$} & \multicolumn{6}{|c|}{ Placebo $(N=42)$} \\
\hline & \multicolumn{2}{|c|}{$\begin{array}{l}\text { baseline } \\
\text { value }\end{array}$} & \multicolumn{2}{|c|}{$\begin{array}{l}\text { Day } 42 \text { (Visit } 8 \text { ) } \\
\text { value }\end{array}$} & \multicolumn{2}{|c|}{$\begin{array}{l}\text { Change from } \\
\text { baseline }\end{array}$} & \multicolumn{2}{|c|}{$\begin{array}{l}\text { Baseline } \\
\text { value }\end{array}$} & \multicolumn{2}{|c|}{$\begin{array}{l}\text { Day } 42 \text { (Visit } 8) \\
\text { value }\end{array}$} & \multicolumn{2}{|c|}{$\begin{array}{l}\text { Change from } \\
\text { baseline }\end{array}$} \\
\hline & Mean & SD & Predose & $\begin{array}{l}2 \mathrm{~h} \text { post- } \\
\text { dose }\end{array}$ & Predose & $\begin{array}{l}2 \mathrm{~h} \text { post- } \\
\text { dose }\end{array}$ & Mean & SD & Predose & $\begin{array}{l}2 \mathrm{~h} \text { post- } \\
\text { dose }\end{array}$ & Predose & $\begin{array}{l}\text { 2-h post } \\
\text { dose }\end{array}$ \\
\hline Heart rate $(\mathrm{bpm})$ & 70.7 & 11.7 & 80.5 & 82.7 & 9.5 & 11.4 & 69.3 & 9.59 & 71.3 & 68.6 & 2.9 & 0.1 \\
\hline $\begin{array}{l}\text { Systolic blood pressure } \\
(\mathrm{mmHg})\end{array}$ & 117 & 11.8 & 121 & 123 & 2.4 & 5.3 & 119 & 12.2 & 116 & 121 & -3.3 & 0.8 \\
\hline $\begin{array}{l}\text { Diastolic blood } \\
\text { pressure }(\mathrm{mmHg})\end{array}$ & 75.7 & 8.8 & 78.9 & 81.2 & 2.8 & 5.4 & 76.2 & 8.76 & 75.6 & 77.3 & -0.5 & 1.2 \\
\hline $\begin{array}{l}\text { QTcF interval, } \\
\text { aggregate }(\mathrm{msec})\end{array}$ & 409 & 19.6 & 407 & 409 & -1.8 & -0.2 & 408 & 18.1 & 411 & 410 & 2.6 & -0.3 \\
\hline
\end{tabular}

bpm beats per minute, $C R$ controlled release, $Q T c F$ corrected QT interval using Fridericia's formula, $S D$ standard deviation

binding study (data on file), it is possible that the hydrolysis metabolite contributes to the clinical profile of mazindol CR.

Results of this study should be considered in light of several potential limitations: (1) the sample size in this study was relatively small, though very solid for a phase II trial. Larger $n$ studies more typical of phase III should be undertaken. (2) A flexible dose design was used, replicating the approach used in clinical practice. However, this design does not aid in determination of the optimal dose of mazindol CR. Future research should include a fixed-dose trial. (3) The highest dose studied here was $3 \mathrm{mg}$. A few subjects $(n=10)$ had an optimal response to $2 \mathrm{mg}$, but most continued to $3 \mathrm{mg}$. However, given the generally favorable tolerability profile, it is possible that a higher dose might have been tolerated and might have produced a larger response in some of the remainder of the subjects who received $3 \mathrm{mg}$. (4) This study used a weekly dose titration design, and only evaluated the efficacy of mazindol CR versus placebo at weekly intervals. Therefore, time to onset of effect cannot be determined from these data; it is possible that response could be achieved faster than it was in this study if a different titration approach were used. (5) The current study was designed to demonstrate acute effects of mazindol CR, and was therefore limited to 6 weeks. Longer-term efficacy will need to be confirmed in later clinical trials. (6) In this study, women were overrepresented ( $58 \%$ of the sample). However, it is generally thought that gender does not moderate the phenotypic presentation of ADHD [31], nor is it thought to moderate treatment response. (7) Although it is well known that adults with ADHD often present with a number of comorbid disorders, the potential impact of comorbidity is not studied until phase IV because if subjects had other psychiatric disorders it would not be possible to know whether the improvement seen with mazindol CR was specific to its effect on ADHD. The approach used here, restricting co-morbidities, is standard for drugs in development.

\section{Conclusions}

This randomized, double-blind, placebo-controlled phase II study in adults with ADHD showed a large magnitude of effect for mazindol CR (effect size 1.09), comparable to what has previously been reported in C2 stimulants, and with good tolerability. The potential availability of a novel medication that has robust efficacy and is well tolerated represents an important unmet need in ADHD. Phase III studies are planned to confirm the safety and efficacy profile of mazindol $\mathrm{CR}$, and to more specifically evaluate dosing recommendations.

Acknowledgements This study was sponsored by NLS-1 Pharma AG. We would like to thank Jennifer Franco and the Worldwide Clinical Trials team for their implementation of the study, Rex Williams and Anginelle Alabanza from Nuventra for their administrative support, and the following investigators and clinical sites: S. Wigal, PhD (AVIDA Inc.); R. Anderson, MD, PhD, and G. Mattingly, MD (Midwest Research Group); V. Arnold, MD (CNS Healthcare, Memphis, TN, USA); M. McDonnell, PhD (South Shore Psychiatric Services); J. Young, MD (Rochester Center for Behavioral Medicine); and N. Jones, MD (CNS Healthcare, Jacksonville, FL, USA).

\section{Compliance with Ethical Standards}

Ethical approval All procedures performed in studies involving human participants were in accordance with the ethical standards of Schulman Institutional Review Board and with the 1964 Helsinki Declaration and its later amendments or comparable ethical standards.

Informed consent Informed consent was obtained from all individual participants included in the study prior to any study procedures.

Funding This study was sponsored by NLS-1 Pharma AG. The open access fee was paid by NLS-1 Pharma AG. 
Conflict of interest The study was sponsored by NLS-1 Pharma AG. All coauthors are paid consultants of NLS-1 Pharma AG. EK is the inventor of the patent for the use of mazindol in ADHD and VS is the inventor of the patent for mazindol CR. Other COIs including as Consultant, Advisory Board, Research Support: Akili Interactive (TW JN SW), Alcobra (JN), Arbor (JN), Cingulate (JN SW), Enzymotec (JN), Ironshore (TW SW JN), KenPharm (JN), Lundbeck (JN), Medic $(\mathrm{JN})$, Neos (JN), Neurovance (TW SW), NFL (JN), Pfizer (SW) Purdue (TW SW), Rho (SW), Rhodes (TW SW JN), Shire (TW SW JN), Sunovion (TW SW JN), Supernus (JN), Tris Pharma (TW SW).

Open Access This article is distributed under the terms of the Creative Commons Attribution-NonCommercial 4.0 International License (http://creativecommons.org/licenses/by-nc/4.0/), which permits any noncommercial use, distribution, and reproduction in any medium, provided you give appropriate credit to the original author(s) and the source, provide a link to the Creative Commons license, and indicate if changes were made.

\section{References}

1. Clemow DB, Walker DJ. The potential for misuse and abuse of medications in ADHD: a review. Postgrad Med. 2014;126(5):64-81.

2. Swanson J, Baler RD, Volkow ND. Understanding the effects of stimulant medications on cognition in individuals with attentiondeficit hyperactivity disorder: a decade of progress. Neuropsychopharmacology. 2011;36(1):207-26.

3. Faraone SV, Glatt SJ. A comparison of the efficacy of medications for adult attention-deficit/hyperactivity disorder using metaanalysis of effect sizes. J Clin Psychiatry. 2010;71(6):754-63.

4. Antshel KM, Hargrave TM, Simonescu M, Kaul P, Hendricks K, Faraone SV. Advances in understanding and treating ADHD. BMC Med. 2011;10(9):72.

5. Nittur N, Konofal E, Dauvilliers Y, Franco P, Leu-Semenescu S, Cock VC, et al. Mazindol in narcolepsy and idiopathic and symptomatic hypersomnia refractory to stimulants: a long-term chart review. Sleep Med. 2013;14(1):30-6.

6. Konofal E, Zhao W, Laouenan C, Lecendreux M, Kaguelidou F, Benadjaoud L, et al. Pilot Phase II study of mazindol in children with attention deficit/hyperactivity disorder. Drug Des Dev Ther. 2014;8:2321-32.

7. Brantley S, Hussey B, Williams R, Schmith V. Pharmacokinetics of mazindol and its hydrolysis metabolite after administration of a single dose of mazindol CR in healthy subjects. In: Annual meeting for the American society of clinical pharmacology and therapeutics; 2018.

8. Schwartz MD, Kilduff TS. The neurobiology of sleep and wakefulness. Psychiatr Clin N Am. 2015;38(4):615-44.

9. Alvarez B, Dahlitz M, Grimshaw J, Parkes JD. Mazindol in longterm treatment of narcolepsy. Lancet (London, England). 1991;337(8752):1293-4.

10. Parkes JD, Schachter M. Mazindol in the treatment of narcolepsy. Acta Neurol Scand. 1979;60(4):250-4.

11. Sheehan DV, Lecrubier Y, Sheehan KH, Amorim P, Janavs J, Weiller E, et al. The Mini-International Neuropsychiatric Interview (M.I.N.I.): the development and validation of a structured diagnostic psychiatric interview for DSM-IV and ICD-10. J Clin Psychiatry. 1998;59(Suppl 20):22-33 (quiz 4-57).

12. American Psychiatric Association. Diagnostic and statistical manual of mental disorders, fifth edition (DSM5). Washington, D.C.: American Psychiatric Association; 2013.

13. Wigal T, Wigal SB, Steinhoff KM, Kollins S, Newcorn JH, Steinberg-Epstein R, Kapelinski A, Bowie J, Gehricke J, \&
Swanson JM. Establishing a Clinical Diagnosis of ADHD in Adults: the QUEST Method. Advan ADHD. 2007; 2(1):17-24.

14. Sallee FR, Kollins SH, Wigal TL. Efficacy of guanfacine extended release in the treatment of combined and inattentive only subtypes of attention-deficit/hyperactivity disorder. J Child Adolesc Psychopharmacol. 2012;22(3):206-14.

15. Reimherr FW, Williams ED, Strong RE, Mestas R, Soni P, Marchant BK. A double-blind, placebo-controlled, crossover study of osmotic release oral system methylphenidate in adults with ADHD with assessment of oppositional and emotional dimensions of the disorder. J Clin Psychiatry. 2007;68(1):93-101.

16. Spencer TJ, Adler LA, McGough JJ, Muniz R, Jiang H, Pestreich L. Efficacy and safety of dexmethylphenidate extended-release capsules in adults with attention-deficit/hyperactivity disorder. Biol Psychiat. 2007;61(12):1380-7.

17. Huss M, Ginsberg Y, Tvedten T, Arngrim T, Philipsen A, Carter $\mathrm{K}$, et al. Methylphenidate hydrochloride modified-release in adults with attention deficit hyperactivity disorder: a randomized double-blind placebo-controlled trial. Adv Ther. 2014;31(1):44-65.

18. Adler LA, Goodman DW, Kollins SH, Weisler RH, Krishnan S, Zhang Y, et al. Double-blind, placebo-controlled study of the efficacy and safety of lisdexamfetamine dimesylate in adults with attention-deficit/hyperactivity disorder. J Clin Psychiatry. 2008;69(9):1364-73.

19. Wigal T, Brams M, Gasior M, Gao J, Giblin J. Effect size of lisdexamfetamine dimesylate in adults with attention-deficit/hyperactivity disorder. Postgrad Med. 2011;123(2):169-76.

20. Weisler RH, Biederman J, Spencer TJ, Wilens TE, Faraone SV, Chrisman AK, et al. Mixed amphetamine salts extended-release in the treatment of adult ADHD: a randomized, controlled trial. CNS Spectr. 2006;11(8):625-39.

21. Frick G, Yan B, Adler LA. Triple-bead mixed amphetamine salts (SHP465) in adults with ADHD: results of a phase 3, doubleblind, randomized, forced-dose trial. $\mathrm{J}$ Atten Disord. 2017;01:1087054717696771.

22. Young JL, Sarkis E, Qiao M, Wietecha L. Once-daily treatment with atomoxetine in adults with attention-deficit/hyperactivity disorder: a 24-week, randomized, double-blind, placebo-controlled trial. Clinical neuropharmacology. 2011;34(2):51-60.

23. Taylor D, Paton C, Kapur S. The Maudsley prescribing guidelines in psychiatry. West Sussex: Wiley-Blackwell; 2003.

24. Kollins SH, Jain R, Brams M, Segal S, Findling RL, Wigal SB, et al. Clonidine extended-release tablets as add-on therapy to psychostimulants in children and adolescents with ADHD. Pediatrics. 2011;127(6):e1406-13.

25. Lasky AK, Weisner TS, Jensen PS, Hinshaw SP, Hechtman L, Arnold LE, et al. ADHD in context: Young adults' reports of the impact of occupational environment on the manifestation of ADHD. Soc Sci Med (1982). 2016;161:160-8.

26. Biederman J, Fried R, Hammerness P, Surman C, Mehler B, Petty $\mathrm{CR}$, et al. The effects of lisdexamfetamine dimesylate on the driving performance of young adults with ADHD: a randomized, double-blind, placebo-controlled study using a validated driving simulator paradigm. J Psychiatr Res. 2012;46(4):484-91.

27. Bejerot S, Ryden EM, Arlinde CM. Two-year outcome of treatment with central stimulant medication in adult attention-deficit/ hyperactivity disorder: a prospective study. J Clin Psychiatry. 2010;71(12):1590-7.

28. Ginsberg Y, Hirvikoski T, Grann M, Lindefors N. Long-term functional outcome in adult prison inmates with ADHD receiving OROS-methylphenidate. Eur Arch Psychiatry Clin Neurosci. 2012;262(8):705-24.

29. Spencer T, Biederman J, Wilens T, Prince J, Hatch M, Jones J, et al. Effectiveness and tolerability of atomoxetine in adults with 
attention deficit hyperactivity disorder. Am J Psychiatry. 1998;155(5):693-5.

30. Smith RG, Innes JA, Munro JF. Double-blind evaluation of mazindol in refractory obesity. BMJ. 1975;3(5978):284.
31. Ramtekkar UP, Reisesen AM, Todorov AA, Todd RD. Sex and age differences in ADHD symptoms and diagnoses: implications for DSM5 and ICD-11. J Am Acad Child Adolesc Psychiatry. 2010;49(30):217-28. 